\title{
A simple and practical method that prepares high molecular weight DNA ladders
}

\author{
JUN-HE ZHANG, RUI YANG, TIAN-YUN WANG, WEI-HUA DONG, FANG WANG and LI WANG
}

Department of Biochemistry and Molecular Biology, Xinxiang Medical University, Xinxiang, Henan 453003, P.R. China

Received April 20, 2012; Accepted August 24, 2012

DOI: $10.3892 / \mathrm{mmr} .2012 .1061$

\begin{abstract}
The purpose of the current study was to report a simple and practical method to prepare high molecular weight (mw) DNA ladders. The method involves 1,000-4,000-base pairs (bp) DNA fragments being amplified by polymerase chain reaction (PCR), using $\lambda$ DNA as a template. The constructed plasmids are digested by restriction endonucleases to produce 5-, 6-, 8- and 10-kb DNA fragments, followed by purification and precipitation with ethanol, and mixed proportionally. The 1,000-4,000-bp DNA fragments were successfully generated by PCR and 5-, 6-, 8- and 10-kb DNA fragments were obtained through the digestion of the plasmids. The bands of the prepared high mw DNA ladder were clear and may aid future molecular biology studies.
\end{abstract}

\section{Introduction}

DNA molecular weight (mw) standard controls of nucleic acids, also known as DNA ladders, are widely used in molecular biology studies to determine the mw or the base pair (bp) length of nucleic acids. The DNA ladder is also used to quantitatively analyze target DNA fragments. At present, there are two ways to prepare a DNA ladder: i) amplification by polymerase chain reaction (PCR) $(1,2)$; and ii) digestion of plasmid DNA by restriction endonucleases $(3,4)$. However, each of these methods have advantages and disadvantages. The former achieves regular bands, but it is difficult to amplify DNA fragments of a high mw. The latter involves the preparation of the DNA ladder mostly from bacteriophages or plasmids, with digestion of the purified DNA by restriction endonucleases, but this process is complex and produces unevenly distributed DNA fragments, particularly for the preparation of large quantities of DNA ladders. The present study describes a method that is based on the combination of PCR amplification and plasmid digestion by restriction endonucleases to prepare a

Correspondence to: Dr Tian-Yun Wang, Department of Biochemistry and Molecular Biology, Xinxiang Medical University, Jinsui Road, Xinxiang, Henan 453003, P.R. China

E-mail:wty@xxmu.edu.cn

Key words: DNA ladder, polymerase chain reaction, restriction endonuclease digestion high mw DNA ladder. The results show that the prepared DNA ladder bands were clear, accurate and cheap and may be used as a standard in future molecular biology experiments.

\section{Materials and methods}

PCR primers. According to the $\lambda$ phage DNA sequence (GenBank accession no. J02459), pairs of 1,000-, 2,000-, 3,000- and 4,000-bp primers were designed with Primer 5.0 software and were obtained from Shanghai Sangon Co., Ltd. (Shanghai, China). The primers are shown in Table I.

PCR amplification. DNA fragments of 1,000-4,000-bp were amplified by PCR. The reaction mixture (100 $\mu \mathrm{l})$ for each quantitative PCR contained $100 \mathrm{ng}$ template DNA, $0.2 \mathrm{mM}$ dNTP, 10 mM Tris-Cl (pH 8.8), $1.5 \mathrm{mM} \mathrm{MgCl}$, $50 \mathrm{mM} \mathrm{KCl}$, $0.1 \mathrm{mM}$ of each primer and 2.5 units Taq DNA polymerase. All PCR procedures of these DNA fragments were adopted by the improved touch-down PCR method (5) and DNA fragments were amplified using various PCR procedures. The specific PCR procedures were as follows: the PCR conditions of 1,000and 2,000-bp included a temperature profile of 30 cycles, which included 2 cycles at $95^{\circ} \mathrm{C}$ for $40 \mathrm{sec}, 60^{\circ} \mathrm{C}$ for $50 \mathrm{sec}$ and $72^{\circ} \mathrm{C}$ for $50 \mathrm{sec}, 2$ cycles $95^{\circ} \mathrm{C}$ for $40 \mathrm{sec}, 59^{\circ} \mathrm{C}$ for $50 \mathrm{sec}$ and $72^{\circ} \mathrm{C}$ for $50 \mathrm{sec}, 2$ cycles for every annealing temperature interval one temperature, until $56^{\circ} \mathrm{C}$ polishing 20 cycles. The PCR conditions of 3,000- and 4,000-bp included a temperature profile of 30 cycles, which contained 2 cycles at $95^{\circ} \mathrm{C}$ for $40 \mathrm{sec}, 65^{\circ} \mathrm{C}$ for $1 \mathrm{~min}$ and $72^{\circ} \mathrm{C}$ for $2 \mathrm{~min}, 2$ cycles $95^{\circ} \mathrm{C}$ for $40 \mathrm{sec}, 64^{\circ} \mathrm{C}$ for $1 \mathrm{~min}$ and $72^{\circ} \mathrm{C}$ for $2 \mathrm{~min}, 2$ cycles for every annealing temperature interval one temperature, until $61^{\circ} \mathrm{C}$ polishing 20 cycles.

Construction, purification and identification of plasmids. The construction of high mw plasmids, including 5-, 6-, 8- and $10-\mathrm{kb}$ was carried out as described previously (6), purified with a plasmid DNA purification kit and identified with endonuclease HindIII. The undigested plasmid of corresponding mw was used as the control and then electrophoresed.

Electrophoresis, purification and sequencing. The PCR products of 1,000- and 2,000-bp were detected by $1 \%$ agarose gel electrophoresis at $120 \mathrm{~V}$ for $30 \mathrm{~min}$. The PCR products of 3,000- and 4,000-bp, the undigested plasmids and the restriction endonuclease were detected by $0.8 \%$ agarose gel at $120 \mathrm{~V}$ for $30 \mathrm{~min}$. The PCR products and plasmid DNA were recovered 
Table I. Primers used in this study.

Length (bp)

Primers

Melting temperature $\left({ }^{\circ} \mathrm{C}\right)$

\begin{tabular}{lll}
\hline 1,000 & 5'-GCGGCACGGAGTGGAGCAAG-3' & 66.00 \\
& 5'-GTTATCGAAATCAGCCACAGGGC-3' & 63.68 \\
2,000 & 5'-GCAGTGACACTGCGCTGGATC-3' & 61.90 \\
& 5'-GTTATCGAAATCAGCCACAGGGC-3' & 63.68 \\
3,000 & 5'-CAGGCCCGCAGTTATCAGGTC-3' & 63.87 \\
& 5'-GTTATCGAAATCAGCCACAGGGC-3' & 63.68 \\
& 5'-CAGCATGCCACGTAAGCGAAACAAAAA-3' & 62.00 \\
& 5'-CACGGAAAAAGAGACGCAGAAACAGC-3' & 63.52 \\
\hline
\end{tabular}
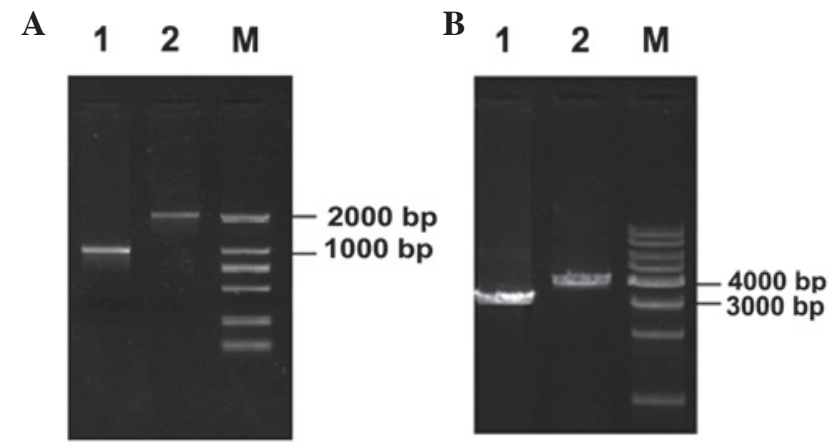

Figure 1. DNA fragments (1,000-4,000-bp) were amplified by PCR. (A) The electrophoresis results of 1,000-bp (lane 1), 2,000-bp (lane 2), DL200 (M). (B) The electrophoresis results of 3,000-bp (lane 1), 4,000-bp (lane 2), 1-kb DNA ladder (M) in (B). PCR, polymerase chain reaction.

using the agarose gel purification kit according to the manufacturer's instructions, followed by sequencing by Shanghai Sangon Co., Ltd. The generated sequences were compared with BLAST (http://www.ncbi.nlm.nih.gov/ blast/Blast.cgi).

Preparation of a high mw DNA ladder. The PCR products and linear plasmids were extracted by phenol/chloroform and precipitated with ethanol, then dissolved in TE $(10 \mathrm{mM}$ Tris-HCl, 1 mM EDTA) buffers and had their UV absorbance analyzed at $260 \mathrm{~nm}$. According to the special proportions, various sizes of DNA fragments were mixed and added to $10 \mathrm{X}$ loading buffer and were then ready for use. The prepared DNA ladder was then frozen at $-20^{\circ} \mathrm{C}$.

\section{Results}

PCR amplification. All DNA fragments of 1,000-4,000-bp were amplified successfully by PCR. As shown in Fig. 1, DNA fragments had high specificity and the sizes of the amplified PCR products were consistent with those expected.

Purification and identification of plasmids. The 4 plasmids and their restriction endonuclease analyses are shown in Figs. 2 and 3. Following the digestion of these constructed vectors by HindIII, revealing the linearized DNA strands, the results of the restriction were consistent with those expected, the above results indicate that 4 plasmids had been successfully constructed.

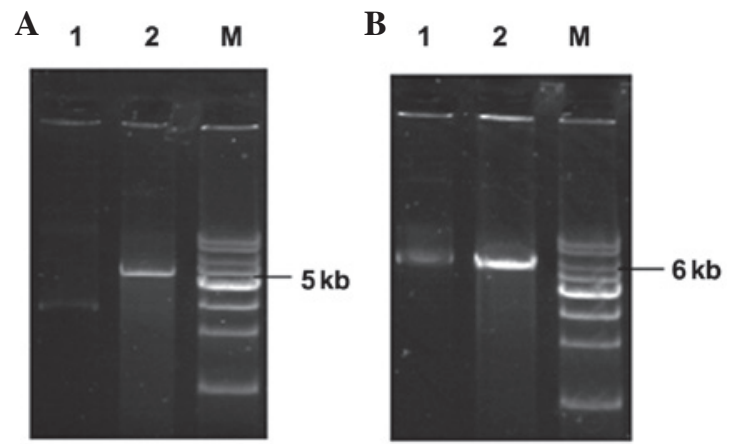

Figure 2. Purification and identification of 5- and 6-kb. (A) The electrophoresis results of 5-kb (lane 1), the linearized strand of 5-kb digested by HindIII (lane 2), 1-kb DNA ladder (M). (B) The electrophoresis results of 6-kb (lane 1), the linearized strand of 6-kb digested by HindIII (lane 2), 1-kb DNA ladder (M).
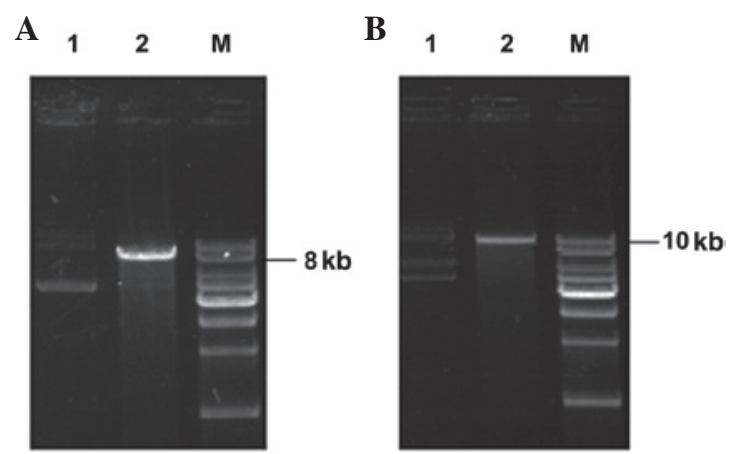

Figure 3. Purification and identification of 8 - and $10-\mathrm{kb}$. (A) The electrophoresis results of $8 \mathrm{~kb}$ (lane 1), the linearized strand of $8 \mathrm{~kb}$ digested by HindIII (lane 2), 1-kb DNA ladder (M). (B) The electrophoresis results of $10 \mathrm{~kb}$ (lane 1), the linearized strand of $10 \mathrm{~kb}$ digested by HindIII (lane 2), 1-kb DNA ladder (M).

Preparation of high mw DNA ladder. Following extraction, purification and quantity analysis, the PCR products and linear plasmids were mixed according to the special proportions, while the 4,000-bp band was doubled to increase the discrimination effect, then added to $10 \mathrm{X}$ loading buffer and was then ready for use. The result of the agarose gel electrophoresis revealed that all the DNA bands were clear and that the ladder was comparable with the commercial version (Fig. 4). 


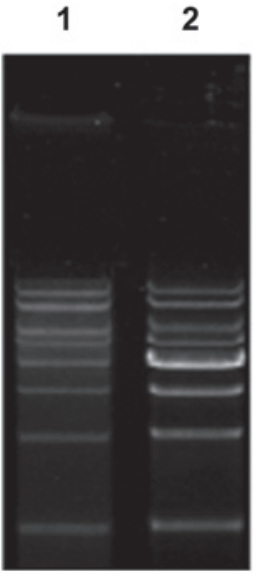

Figure 4. Preparation of high molecular weight DNA ladder. The electrophoresis results of the prepared 1-kb DNA ladder (lane 1), the commercial product of 1-kb DNA ladder (lane 2).

\section{Discussion}

The DNA ladder is a widely applied method in electrophoresis and is valuable in molecular biology experiments. It is used to mark the mw of unknown samples in nucleic acid electrophoresis and further aids the judgement of the properties of DNA samples. DNA ladders have been widely applied in such fields as biotechnology, medicine and agriculture, among others, and the market demand is extremely high. PCR was initiated in 1983 by Mullis et al (7) as a specific DNA amplification technology and has the advantages of easy operation, high sensitivity and specificity and good selectivity, and has been widely applied in the fields of molecular biology, genetics, biochemistry, genetic engineering and forensics (8-10). Although PCR amplification is convenient for preparing the DNA ladder, conventional PCR is designed to amplify one type of DNA fragment, one tube at a time, while the DNA ladder is an integration of several DNA fragments, which makes the technological process more complex and cumbersome (11). In addition, the technology is only suitable for amplifying small DNA fragments, while the corresponding fragments of a high mw DNA ladder are difficult to obtain. Despite certain large fragments being amplified using high-fidelity DNA polymerase, the specificity is poor and production cost is high and cannot meet the experimental demand. Another routine method of preparing a DNA ladder is using bacteriophages or plasmids which are digested by restriction endonucleases $(12,13)$. This process requires the construction of a series of vectors for preparing the DNA ladder, further digesting the purified DNA with certain restriction endonucleases and subsequently the combinations of DNA fragments that were required are obtained $(14,15)$. This process is laborious, time consuming and material- and equipment-intensive, involving the propagation of the virus or plasmid in the appropriate host organism and the purification and digestion of the genomic or plasmid DNA from the nucleic acids of the host. Since the corresponding restriction enzyme sites of bacteriophages or plasmid DNA are not well balanced, the distribution of the prepared DNA ladder is irregular and the gaps of the DNA bands are variable in size and not convenient (16).

Based on the analysis and research of the advantages and disadvantages of the above two methods, the methods of PCR amplification and plasmid digestion by restriction endonucleases were adopted in the current study to prepare a high mw DNA ladder. In the current study, 1,000-4,000-bp DNA bands were amplified by PCR and the larger DNA bands, including 5-, 6-, 8and $10-\mathrm{kb}$, were obtained by restriction endonuclease digestion of the purified plasmids. These DNA fragments were extracted with phenol/chloroform and precipitated with ethanol, further mixed according to the special proportions and added to $10 \mathrm{X}$ loading buffer to obtain the high mw DNA ladder. Compared with commercial DNA ladders, this method was simple, practical and low cost, and the DNA bands were clear. It may also be adjusted to any size of mw standard in a certain range according to the experimental requirement and may be used as a standard in molecular experiments. In short, a new method of preparing high mw DNA ladders was developed in this study.

\section{Acknowledgements}

This work was supported by grants from the National Natural Science Foundation of China (30970055), Henan Province (122102310194; 12A310005) and the key research areas bidding subject of Xinxiang Medical University (ZD2011-36).

\section{References}

1. Wu J and Ye C: Tandem PCR: a novel and efficient unit amplification model for the preparation of small DNA fragments. Mol Biol Rep 38: 2729-2731, 2011.

2. Wang TY, Guo L and Zhang JH: Preparation of DNA ladder based on multiplex PCR technique. J Nucleic Acids 25: 421803, 2010.

3. Dodgson JB, Cheng HH and Okemoto R: DNA marker technology: a revolution in animal genetics. Poult Sci 76: 1108-1114, 1997.

4. Chen Z, Wu J, Li X, Ye C and Wenxing H: Novel strategies to construct complex synthetic vectors to produce DNA molecular weight standards. Mol Biotechnol 42: 128-133, 2009.

5. Schunck B, Kraft W and Truyen U: A simple touch-down polymerase chain reaction for the detection of canine parvovirus and feline panleukopenia virus in feces. J Virol Methods 55: 427-433, 1995.

6. Sambrook J and Russell DW (eds): Molecular Cloning: A Laboratory Manual. 3rd edition. Cold Spring Harbor Laboratory Press, New York, NY, 2001.

7. Mullis K, Faloona F, Scharf S, Saiki R, Horn G and Erlich H: Specific enzymatic amplification of DNA in vitro: the polymerase chain reaction. Cold Spring Harb Symp Quant Biol 51: 263-273, 1986

8. Ting NC, Zaki NM, Rosli R, et al: SSR mining in oil palm EST database: application in oil palm germplasm diversity studies. J Genet 89: 135-145, 2010.

9. Lee JH, Shin SR and Cho JH: Evaluation of direct immunofluorescence test with PCR for detection of novel influenza A (H1N1) virus during 2009 pandemic. Yonsei Med J 52: 680-682, 2011.

10. Bellstedt DU, Pirie MD, Visser JC, de Villiers MJ and Gehrke B: A rapid and inexpensive method for the direct PCR amplification of DNA from plants. Am J Bot 97: e65-e68, 2010.

11. Dawson EP: Method for the multiplexed preparation of nucleic acid molecular weight markers and resultant products. US Patent 5,714,326. Filed January 3, 1996; issued February 3, 1998.

12. Ye C, Gu J, Chen S, Deng A, Li YZ and Li D: Unit cloning and amplification as novel and universal strategies for complex vector construction and small DNA fragment preparation. Electrophoresis 31: 2929-2935, 2010.

13. Hu A-li W, Hartley JL and Jordan HJ: Nucleic acid ladders. US Patent 6,924,098. Filed December 3, 1999; issued August 2, 2005.

14. Barvish Z, Davis C and Gitelman I: A wide-range, low-cost $150 \mathrm{bp}$ ladder for sizing DNA fragments between 150 and 4500 bp. Electrophoresis 28: 900-902, 2007.

15. Cole KD: Preparative separation of plasmid and bacterial artificial chromosome DNA by density gradient electrophoresis in the presence of linear polymers. Electrophoresis 19: 3062-3068, 1998.

16. Hyman ED: Method of making DNA ladders. US Patent 5,939,293. Filed June 5, 1998; issued August 17, 1999. 